\title{
Micronutrient deficiency in obese subjects undergoing low calorie diet
}

\author{
Antje Damms-Machado ${ }^{1}$, Gesine Weser ${ }^{1}$ and Stephan C Bischoff ${ }^{2 *}$
}

\begin{abstract}
Background: The prevalence of micronutrient deficiencies is higher in obese individuals compared to normalweight people, probably because of inadequate eating habits but also due to increased demands among overweight persons, which are underestimated by dietary reference intakes (DRI) intended for the general population. We therefore evaluated the dietary micronutrient intake in obese individuals compared to a reference population and DRI recommendations. Furthermore, we determined the micronutrient status in obese subjects undergoing a standardized DRI-covering low-calorie formula diet to analyze if the DRI meet the micronutrient requirements of obese individuals.
\end{abstract}

Methods: In 104 subjects baseline micronutrient intake was determined by dietary record collection. A randomly assigned subgroup of subjects $(n=32)$ underwent a standardized DRI-covering low-calorie formula diet over a period of three months. Pre- and post-interventional intracellular micronutrient status in buccal mucosa cells (BMC) was analyzed, as well as additional micronutrient serum concentrations in 14 of the subjects.

Results: Prior to dietetic intervention, nutrition was calorie-rich and micronutrient-poor. Baseline deficiencies in serum concentrations were observed for 25-hydroxyvitamin-D, vitamin C, selenium, iron, as well as ß-carotene, vitamin C, and lycopene in BMC. After a three-month period of formula diet even more subjects had reduced micronutrient levels of vitamin C (serum, BMC), zinc, and lycopene. There was a significant negative correlation between lipophilic serum vitamin concentrations and body fat, as well as between iron and C-reactive protein.

Conclusions: The present pilot study shows that micronutrient deficiency occurring in obese individuals is not corrected by protein-rich formula diet containing vitamins and minerals according to DRI. In contrast, micronutrient levels remain low or become even lower, which might be explained by insufficient intake, increased demand and unbalanced dispersal of lipophilic compounds in the body.

Trial registration: The study was registered at ClinicalTrials.gov (NCT01344525). The study protocol comprises only a part of the approved trial protocol.

Keywords: Obesity, Low calorie diet, Weight loss, Micronutrient deficiency, Dietary reference intake

\section{Background}

In general, occurrence of malnutrition is thought to be disease-related and/or associated with undernourishment. During the past few years, evidence has been raised that obesity can also be associated with substantial nutrient deficiencies [1-5]. In fact, the prevalence of micronutrient deficiencies in obese individuals is higher compared to normal weight controls of the same age

\footnotetext{
*Correspondence: bischoff.stephan@uni-hohenheim.de

${ }^{2}$ Department of Nutritional Medicine, University of Hohenheim, Fruwirthstr.

12, ss70599, Stuttgart, Germany

Full list of author information is available at the end of the article
}

and sex [6,7], and affects several micronutrients such as zinc $[4,8]$, selenium $[4,6,8,9]$, folate $[4,6,8,10]$, vitamin $B_{1}$ [11], vitamin $B_{12}[4,6,8,10,12]$, vitamin $A[6,8]$, vitamin $E$ [4,6], and 25-hydroxyvitamin D [25(OH)D] [4,6,8,11]. Imbalances or deficiencies of essential micronutrients significantly influence day-to-day performance, behavior and emotional state, as well as intellectual and physical activity [13-15]. It has been hypothesized that toxic byproducts of incomplete biochemical reactions resulting from excessive intake of kilocalories and states of micronutrient deficiencies could lead to further weight gain or development of associated metabolic diseases $[13,16]$.

\section{Biomed Central}


Considering the worldwide prevalence of obesity, a significant part of the population could be afflicted by this type of micronutrient deficiency, even in wealthy Western countries.

The dietary reference intakes (DRI) for daily supply of vitamins and mineral nutrients apply to healthy, normal weight individuals. They account for individual variations and distinguish between age groups and sex $[17,18]$, but they do not apply to patients with metabolic alterations or other disease, or individuals using pharmaceuticals on a regular basis. Hence, DRI do not necessarily meet the metabolic needs of obese individuals. Especially in physiologic stress situations like significant weight loss or periods of weight cycling, obese patients potentially need different amounts of micronutrients.

The first aim of this pilot study was to investigate the micronutrient intake in obese subjects compared to a reference population and DRI recommendations. Second aim was to determine both serum and intracellular micronutrient status after a standardized DRI-covering low-calorie formula diet over three months in order to analyze if DRI for micronutrients apply to obese patients in a period of major weight loss. This setting was chosen, because it offers a unique possibility to study this issue using an entirely standardized diet consumed by high-grade obese individuals over a longer-term period.

\section{Methods}

\section{Intervention and study population}

This pilot study included obese individuals participating in a multidisciplinary weight loss program (OPTIFAST ${ }^{\circledR} 52$ ) causing an average weight loss of $26.0 \mathrm{~kg}$ in men and $19.6 \mathrm{~kg}$ in women within one year [19]. Briefly, the program consists of a five-phase lifestyle modification program designed for 52 weeks, including (i) a 1-week introduction during which a detailed nutrition analysis is performed; (ii) a 12 week period of low-calorie diet (LCD) (800 kcal/day) during which participants consume a formula diet exclusively (daily consumption of 5 sachets at $160 \mathrm{kcal} \mathrm{each}$, Optifast $800^{\circledR}$ formula, Nestlé Inc.); (iii) a 6 weeks refeeding phase, (iv) a 7 weeks stabilization phase and (v) a 26 weeks maintenance phase. We previously reported more detailed information about the program [19]. The five daily consumed formula meals in the second phase contain vitamins, minerals and trace elements according to DRI for healthy adults (Table 1), except for the flavor potato/leek, which contains less amounts of vitamin C, vitamin $B_{12}$, folate and calcium. However, flavor selection was documented, recording that the latter one was only consumed occasionally.

To determine micronutrient intake in obese individuals we analyzed dietary record data obtained during the introduction week from all participants enrolled from $02 / 2006$ to $02 / 2010(n=104)$. A randomly assigned subgroup of subjects $(n=32)$ participated in a pilot study, and was followed up for micronutrient measurement before and after the three-month formula diet period (LCD intervention group). Patients with a history of bariatric surgery were excluded from study participation. The measurements were performed by intracellular micronutrient analysis in buccal mucosa cells (BMC) and by additional serum micronutrient analysis in 14 of the subjects. The latter subjects did not differ in initial body weight and weight loss to the whole LCD intervention group. For 9 subjects, long-term data on intracellular vitamin concentrations were also obtained at the end of the program year, 9 months after completion of the LCD phase. The nutrients evaluated in this study were vitamin C (BMC, serum, leukocytes), vitamin E (BMC, serum), lycopene (BMC), $\beta$-carotene (BMC), vitamin A, $25(\mathrm{OH}) \mathrm{D}$, vitamin $\mathrm{B}_{12}$, folate, selenium, iron, zinc and calcium (all serum). Deficiency was defined as a concentration below the reference interval: vitamin A $0.2-1.2 \mathrm{mg} /$ $\mathrm{ml}$, vitamin E 5-16 $\mathrm{mg} / \mathrm{ml}$ (serum) $/ 9.5-20.3 \mathrm{pmol} / \mu \mathrm{g}$ DNA (BMC), 25(OH)D, 20-70 ng/ml, vitamin C 28.3$85.1 \mu \mathrm{g} / \mathrm{ml}$ (serum)/57-114 nmol/10 ${ }^{8}$ cells (leukocytes)/

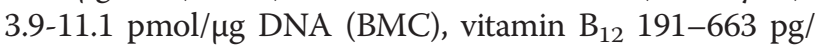
$\mathrm{ml}$, folate $4.6-18.7 \mathrm{ng} / \mathrm{ml}$, selenium $74-139 \mu \mathrm{g} / \mathrm{ml}$, iron $40-170 \mu \mathrm{g} / \mathrm{dl}$, zinc $70-150 \mu \mathrm{g} / \mathrm{dl}$, calcium $2.2-2.6 \mathrm{mmol} / \mathrm{l}$, $\beta$-carotene 0.1-05 pmol/ $\mu \mathrm{g}$ DNA, and lycopene 0.1-05 $\mathrm{pmol} / \mu \mathrm{g}$ DNA. Moreover, C-reactive protein (CRP) concentrations were analyzed in serum samples. Drug use was monitored and documented on standardized forms. We calculated body mass index (BMI) and relative weight loss in percent $(\mathrm{RWL}$; $=100 \mathrm{x} \Delta$ weight loss in $\mathrm{kg} /$ initial body weight in $\mathrm{kg}$ ). Body composition was analyzed using bioelectrical impedance analysis at all study visits (Data Input Nutriguard M, Darmstadt, Germany). The study protocol was part of a multicenter clinical trial, research project "Obesity and the gastrointestinal tract" (ClinicalTrials.gov identifier: NCT01344525), approved by the ethics committee of the University Hospital of Tübingen, Germany. Informed consent was obtained from every subject prior to participation.

\section{Dietary records}

Food intake was recorded using a predesigned daily journal. Subjects had to document time, amount (in gram) and situation, in which a food or beverage was consumed. They were instructed to: (1) document all consumed foods and beverages in as much detail as possible, (2) to weigh foods (or to estimate doses, if weighing was not possible in some situations), (3) to document food or beverage intake immediately after consumption and (4) not to change usual eating habits. Data analysis was performed using the nutrition software EBISpro, version 8.0 for Windows. In analyzing the eating records, nutrients were studied in 
Table 1 Content of selected micronutrients in the formula diet and comparison with DRI (D-A-CH reference values)

\begin{tabular}{|c|c|c|c|c|c|}
\hline Micronutrient & Unit & Per sachet ${ }^{\text {flavor A }}$ (42 g) & $\%$ of DRI per 5 sachets & Per sachet ${ }^{\text {flavor B }}$ (42 g) & $\%$ of DRI per 5 sachets \\
\hline Vitamin A & $\mathrm{mg}$ & 0.3 & 우188; ठ̂1150 & 0.2 & 우125; đ100 \\
\hline Vitamin D & $\mu g$ & 1.0 & 101 & 1.2 & 118 \\
\hline Vitamin E & $\mathrm{mg}$ & 4.0 & 우142; đ166 & 3.4 & 우122; đ̂143 \\
\hline Vitamin C & $\mathrm{mg}$ & 20.0 & 100 & 10.8 & 54 \\
\hline Vitamin $B_{12}$ & $\mu g$ & 0.6 & 98 & 0.4 & 60 \\
\hline Folate & $\mu \mathrm{g}$ & 80.2 & 100 & 48.0 & 60 \\
\hline Calcium & $\mathrm{mg}$ & 290.6 & 145 & 168.1 & 84 \\
\hline Iron & $\mathrm{mg}$ & 4.0 & ठ133; +199 & 3.8 & ठ127; 9191 \\
\hline Zinc & $\mathrm{mg}$ & 3.0 & ô149; 우213 & 2.3 & ô114; 우163 \\
\hline Selenium & $\mu \mathrm{g}$ & 20.2 & $144-336$ & 13.6 & $97-227$ \\
\hline
\end{tabular}

Flavor A: vanilla, chocolate, strawberry, coffee, and tomato; flavor B: potato/leek.

relation to the DRI (D-A-CH reference values) [18]. The DRI utilized corresponds to the age group and sex. Furthermore, data were compared with the Second National Nutrition Survey (NNSII), which is representative for the German population. The dietary assessment in this survey was performed using controlled interviews according to the diet history method, which were reinforced by dietary record collection and 24 hour-recalls in a representative sub-sample.

\section{Intracellular micronutrient concentrations in buccal mucosa cells (BMC)}

$\mathrm{BMC}$ were collected using a kit from Day-med-concept $\mathrm{GmbH}$, Berlin, Germany. Subjects first had to rinse their mouths with water thoroughly to remove food particles and then brush the inner lining of their cheeks with a soft toothbrush twenty times, twice on each side. The toothbrush was washed in $25 \mathrm{ml} \mathrm{NaCl}$ solution (0.9\%) gently after each brushing. The samples were then centrifuged at 1,600 rpm for 3 minutes. The supernatant was discarded; the cells were completely resuspended in rinsing solution (phosphor float $0.15 \% \mathrm{w} / \mathrm{v}$ ) and centrifuged again at $1,800 \mathrm{rpm}$ for 3 minutes. After removal of the supernatant fraction, the stabilizing solution (heat-sensitive reducing agent $0.09 \% \mathrm{w} / \mathrm{v}$ ) was added; and the cells were resuspended and stored. The micronutrients in $\mathrm{BMC}(\mathrm{pmol} / \mu \mathrm{g}$ DNA) of the samples were measured by BioTeSys GmbH (Esslingen, Germany) using an accredited RP-HPLC method according to DIN EN ISO/IEC 17025. The reference values are based on a statistical distribution reflecting the 25 th and 75 th percentile of a data set covering analysed BMC samples over one year.

Micronutrient concentrations were expressed in pmol/ $\mu \mathrm{g}$ DNA. Micronutrient detection was possible when the amount of DNA in BMC was at least sufficient $(>1 \mu \mathrm{g})$. If the amount of DNA extracted was $<1 \mu \mathrm{g}$, the data was excluded from analysis. Micronutrients below detection limit were defined as suboptimal cellular concentrations according to the analysis laboratory and therefore were included.

\section{Serum concentrations of micronutrients}

For serum micronutrient analysis, blood was collected by venipuncture between 8.00 a.m. and 10.00 a.m. after an overnight fast. Serum was separated by centrifugation at $2,000 \mathrm{x} \mathrm{g}$ for $15 \mathrm{~min}$ at $4^{\circ} \mathrm{C}$. Aliquots were immediately stored at $-80^{\circ} \mathrm{C}$ and sent to an external laboratory on the same day. HPLC was used to assay vitamin A and $\alpha$-tocopherol. Measurement of vitamin $C$, calcium and iron was performed by photometry. Furthermore, serum was analyzed for $25(\mathrm{OH}) \mathrm{D}$ (radioimmunoassay), zinc and selenium (atomic absorption spectrometry) and vitamin $B_{12}$ and folate (luminescence immunoassay).

\section{Vitamin C concentrations in leukocytes}

Isolation of leucocytes for vitamin $\mathrm{C}$ analysis was performed immediately after blood withdrawal. Briefly, sedimentation of erythrocytes was performed in a hermetic tube in dark environment using 6\% Dextran according to the method of Denson et al. [20]. Supernatant was centrifuged for $10 \mathrm{~min}$ at $320 \mathrm{x}$ g. After resuspension with HA buffer lysis of remaining erythrocytes was performed by 5 min incubation with $10 \mathrm{ml}$ ammonium chloride. After centrifugation (10 min, $600 \mathrm{x} \mathrm{g}$ ), leukocytes were manually counted and pellets frozen at $-80{ }^{\circ} \mathrm{C}$ until analysis. Determination of total ascorbic acid concentrations in leukocytes was performed by HPLC. In summary, after thawing, leukocyte pellets reducing agent $(20 \mu \mathrm{l} 20 \%$ TCEP solution [tris (2- carboxyethyl) phosphine hydrochlorid]) was added, thoroughly mixed and incubated on ice for $5 \mathrm{~min}$. For cell lysis $80 \mu \mathrm{l} 10 \%$ meta-phosphoric acid was added, mixed and centrifuged (10 $\mathrm{min}, 13,000 \times \mathrm{g}, 4^{\circ} \mathrm{C}$ ). Ascorbic acid concentrations in the supernatant were determined by UV/ VIS detector at $245 \mathrm{~nm}$.

All samples for vitamin $\mathrm{C}$ analysis were rapidly processed and shielded from light exposure. 


\section{Statistical analysis}

Values are expressed as means $\pm S D$ if not indicated otherwise. For the comparison of dietary record parameters with the reference population, Gaussian distribution was assumed due to sample size $(n=15,371)$. Differences between the obese study population and the NNSII data were analyzed using unpaired t-tests. The paired $t$-test was applied to compare repeated measures of micronutrients. If Gaussian distribution could not be assumed Wilcoxon signed-rank test was used instead of t-tests. Frequencies were analyzed with cross tables according to the method of McNemar. Analysis of covariance (ANCOVA) was performed to control for the effect of sex, age, energy, and medication use on micronutrient concentrations. Relations between continuous variables were analyzed by calculating the Spearman's rank correlation coefficient or, in case of normal distribution of the data, the Pearson's correlation coefficient. $\mathrm{P}$ values $<0.001$ were interpreted as statistically highly significant, p-values between 0.001 and $<0.01$ as very significant and p-values between 0.01 and $<0.05$ as significant differences. All analyses were carried out by using the statistics software SPSS, version 19.0 $\left(\right.$ IBM $^{\circledR}$ SPSS $^{\circledR}$, Chicago, IL), and Graph Pad Prism, version 5.0 (GraphPad Software, Inc., La Jolla, CA).

\section{Results}

Baseline characteristics, weight loss and drug intake

Prior to intervention all subjects had at least grade I obesity $\left(\mathrm{BMI} \geq 30 \mathrm{~kg} / \mathrm{m}^{2}\right)$, about $50 \%$ even obesity grade III $\left(B M I \geq 40 \mathrm{~kg} / \mathrm{m}^{2}\right.$ ). The obese study group (dietary records) and the reference population were well matched in respect to age, but the obese group comprised more females (Table 2). BMI of the reference population was significantly lower compared to the obese study group $\left(26.5 \mathrm{~kg} / \mathrm{m}^{2}\right.$ versus $\left.40.9 \mathrm{~kg} / \mathrm{m}^{2}, \mathrm{p}<0.001\right) .32$ out of 104 obese individuals (31\%) underwent the LCD intervention. On average, these subjects lost $16.2 \%$ of initial body weight during the three-month LCD period. The LCD intervention subgroup $(n=9)$, which was followed up until program end (12 months after start of intervention), did not differ in weight loss during the LCD period compared with the whole LCD intervention group (Table 3).

$86 \%$ of the subjects undergoing LCD took medication on a regular basis, which may have resulted in drugnutrient interaction effects, thus influencing micronutrient bioavailability: ACE inhibitor (21\%), proton pump inhibitor (8\%), antidepressants (14\%), L-thyroxine (14\%), biguanide (7\%), insulin (7\%), loop diuretics (8\%), NSAID (7\%) and xanthine oxidase inhibitor (14\%). Frequencies and dosage of medication decreased slightly in $36 \%$ of the cases during the LCD period. Controlling for sex, age, energy intake, and medication use, did not reveal significant effects on micronutrient concentrations.

\section{Micronutrient intake}

Micronutrient intakes in obese subjects are shown in Table 4. Micronutrient intake in female subjects was significantly lower for five micronutrients compared to the reference population, in male subjects for six micronutrients, respectively. Women consumed nine micronutrients in amounts below DRI whereas with men this applied to seven micronutrients. Lowest micronutrient intakes compared to DRI were observed for retinol, $ß$-carotene, vitamin $\mathrm{D}$, folate, iron and iodine ( $>75 \%$ of the obese study population below DRI) and vitamin E, C and calcium $(>50 \%$ respectively).

Micronutrient intake did not differ between the whole study group $(\mathrm{n}=104)$ and the subset of obese individuals undergoing LCD, which were further subjected to intracellular and serum micronutrient analysis.

Micronutrient deficiencies in serum before and after LCD Baseline deficiencies in serum micronutrient concentrations were observed for $25(\mathrm{OH}) \mathrm{D}$, vitamin $\mathrm{C}$, selenium and iron (Table 5). Except for 25(OH)D, the number of cases with deficiencies either remained (selenium, iron, both n.s.) or tended to further increase, which was the case for vitamin $C(+15 \%$ of subjects with deficiency, n.s.).

Table 2 Subjects characteristics of the obese study population (dietary record analysis) and a subgroup undergoing low-calorie diet

\begin{tabular}{lllll}
\hline & $\begin{array}{l}\text { Reference population } \\
\text { (NNSII) }\end{array}$ & $\begin{array}{l}\text { Obese study population } \\
(\mathbf{n}=\mathbf{1 0 4})\end{array}$ & $\begin{array}{l}\text { LCD intervention } \\
\text { group }(\mathbf{n}=\mathbf{3 2})\end{array}$ & $\begin{array}{l}\text { LCD intervention subgroup (follow-up } \\
\text { until program end) ( } \mathbf{n = 9 )}\end{array}$ \\
\hline Sex (\%) & & & & \\
male & 46.2 & 26.9 & 12.5 & 33.3 \\
female & 53.8 & 73.1 & 87.5 & 66.7 \\
Age & 45.8 & $45.8 \pm 11.0$ & $47.0 \pm 10.23$ & $48.9 \pm 8.94$ \\
Weight $[\mathrm{kg}]$ & 76.7 & $117.8 \pm 29.85$ & $118.4 \pm 19.93$ & $125.5 \pm 22.54$ \\
BMI $[\mathrm{kg} / \mathrm{m} 2]$ & 26.5 & $40.9 \pm 7.20$ & $41.8 \pm 7.21$ & $43.0 \pm 6.42$ \\
\hline
\end{tabular}

Data are presented as mean \pm SD. 
Table 3 Weight loss during low-calorie diet $(n=32)$ and further follow-up until program end $(n=9)$

\begin{tabular}{lllll}
\hline & $\begin{array}{l}\text { WL after } \\
\text { LCD } \\
{[\mathbf{k g}]}\end{array}$ & $\begin{array}{l}\text { RWL } \\
\text { after } \\
\text { LCD [\%] }\end{array}$ & $\begin{array}{l}\text { WL 12 at } \\
\text { program } \\
\text { end [kg] }\end{array}$ & $\begin{array}{l}\text { RWL at } \\
\text { program } \\
\text { end [\%] }\end{array}$ \\
\hline $\begin{array}{l}\text { LCD intervention } \\
\text { group }(n=32)\end{array}$ & $19.5 \pm 5.65$ & $16.2 \pm 3.24$ & & \\
$\begin{array}{l}\mathrm{LCD} \text { intervention } \\
\text { subgroup }^{\mathrm{a}}(\mathrm{n}=9)\end{array}$ & $21.8 \pm 8.41$ & $17.0 \pm 4.12$ & $19.9 \pm 15.0$ & $15.5 \pm 10.6$ \\
\hline
\end{tabular}

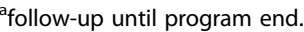

Abbreviations: WL Weight loss, RWL Relative weight loss.

After the formula period, additional deficiency in zinc (7.7\%) and calcium (53.8\%) occurred. Figure 1 shows serum concentrations that decreased (calcium $(\mathrm{p}<0.01)$ and iron $(\mathrm{p}<0.05))$ or increased $(25(\mathrm{OH}) \mathrm{D}(\mathrm{p}<0.01)$, folate $(\mathrm{p}<0.05)$ and zinc $(\mathrm{p}<0.01))$, or remained unchanged (vitamin $\mathrm{C}$ (n.s.)) in the course of intervention using formula diet.

\section{Micronutrient deficiencies in BMC before and after LCD} Intracellular antioxidant status in BMC is displayed in Figure 2. Before intervention, deficiencies were observed for vitamin C (63.3\%), ß-carotene (20.0\%) and lycopene (10.0\%). After the LCD period BMC concentrations of vitamin $C(p<0.05)$ and lycopene $(p<0.05)$ decreased, resulting in a higher percentage of subjects with deficiencies (vitamin $\mathrm{C}+30.2 \%, \mathrm{p}<0.01$ and lycopene $+6.1 \%$, n.s.). At the end of the weight loss program (9 months after termination of the formula diet) antioxidative status was optimal or even above reference range, except for vitamin $\mathrm{C}$ (deficiencies in $77.8 \%$ of subjects), which also tended to improve (n.s.).

\section{Vitamin C in serum, BMC and leukocytes before and after LCD}

No correlation between vitamin $\mathrm{C}$ serum, BMC and leukocyte concentrations was observed. Serum and BMC vitamin $C$ levels tended to decrease during the formula period (serum $59.44 \pm 22.73 \mu \mathrm{mol} / \mathrm{l}$ before intervention, $37.29 \pm 13.48 \mu \mathrm{mol} / \mathrm{l}$ after formula $\operatorname{diet}$ (n.s.), BMC $6.62 \pm 1.52 \mathrm{pmol} / \mu \mathrm{g}$ DNA and $2.95 \pm 1.10 \mathrm{pmol} / \mu \mathrm{g}$ DNA $(\mathrm{p}<0.001)$, respectively), whereas leukocyte vitamin $\mathrm{C}$ concentrations increased $\left(81.64 \pm 16.30 \mathrm{ng} / 10^{8}\right.$ cells to $111.2 \pm 36.32 \mathrm{ng} / 10^{8}$ cells, $\mathrm{p}<0.05$ ) (Figure 3 ).

Table 4 Micronutrient intake of the obese study population compared to DRI and the reference population

\begin{tabular}{|c|c|c|c|c|c|c|c|c|c|c|c|}
\hline \multirow{2}{*}{ Micronutrients } & & \multicolumn{5}{|c|}{ Female subjects $(n=76)$} & \multicolumn{5}{|c|}{ Male subjects $(n=28)$} \\
\hline & & $\overline{D R I^{a}}$ & $\begin{array}{l}\text { Obese study } \\
\text { population }\end{array}$ & $\begin{array}{l}\text { Reference } \\
\text { population } \\
\text { (NNS II) }\end{array}$ & $P^{b}$ & $\begin{array}{l}\text { Obese subjects } \\
\text { [\%] below DRI }\end{array}$ & $\overline{\mathrm{DRI}}$ & $\begin{array}{l}\text { Obese study } \\
\text { population }\end{array}$ & $\begin{array}{l}\text { Reference } \\
\text { population } \\
\text { (NNS II) }\end{array}$ & $P^{b}$ & $\begin{array}{l}\text { Obese subjects } \\
\text { [\%] below DRI }\end{array}$ \\
\hline Retinol & {$[\mu \mathrm{g}]$} & 800 & $629.0 \pm 76.57$ & $600.0 \pm 0.01$ & ns & 86 & 1000 & $594.2 \pm 55.92$ & $1000.0 \pm 0.01$ & $<.001$ & 89 \\
\hline$\beta$-Carotene & {$[\mathrm{mg}]$} & 4.8 & $3.0 \pm 0.24$ & $5.4 \pm 0.04$ & $<.001$ & 86 & 6 & $2.7 \pm 0.31$ & $5.1 \pm 0.04$ & $<.001$ & 93 \\
\hline Vitamin D & {$[\mu \mathrm{g}]$} & 5 & $2.5 \pm 0.32$ & $2.9 \pm 0.03$ & $<.05$ & 87 & 5 & $2.4 \pm 0.31$ & $3.8 \pm 0.04$ & $<.001$ & 93 \\
\hline Vitamin E & {$[\mathrm{mg}]$} & 12 & $11.7 \pm 0.56$ & $13.4 \pm 0.08$ & $<.05$ & 55 & 14 & $11.4 \pm 0.80$ & $16.0 \pm 0.12$ & $<.05$ & 75 \\
\hline Vitamin $B_{1}$ & {$[\mathrm{mg}]$} & 1 & $1.2 \pm 0.04$ & $1.3 \pm 0.01$ & ns & 25 & 1.2 & $1.4 \pm 0.10$ & $1.8 \pm 0.01$ & $<.05$ & 39 \\
\hline Vitamin $B_{2}$ & {$[\mathrm{mg}]$} & 1.2 & $1.4 \pm 0.04$ & $1.7 \pm 0.01$ & $<.05$ & 33 & 1.4 & $1.5 \pm 0.09$ & $2.2 \pm 0.02$ & $<.01$ & 39 \\
\hline Niacin-equivalent & {$[\mathrm{mg}]$} & 13 & $31.2 \pm 0.98$ & $28.6 \pm 0.13$ & ns & 0 & 16 & $34.9 \pm 1.67$ & $39.8 \pm 0.22$ & ns & 0 \\
\hline Vitamin $B_{6}$ & {$[\mathrm{mg}]$} & 1.2 & $1.5 \pm 0.04$ & $2.0 \pm 0.01$ & $<.001$ & 24 & 1.5 & $1.7 \pm 0.09$ & $2.6 \pm 0.02$ & $<.01$ & 43 \\
\hline Folate-equivalent & {$[\mu \mathrm{g}]$} & 400 & $215.2 \pm 8.07$ & $290.0 \pm 1.94$ & $<.001$ & 99 & 400 & $213.4 \pm 11.07$ & $338.0 \pm 3.09$ & $<.001$ & 100 \\
\hline Vitamin $B_{12}$ & {$[\mu \mathrm{g}]$} & 3 & $4.9 \pm 0.31$ & $4.3 \pm 0.02$ & ns & 30 & 3 & $5.7 \pm 0.36$ & $6.5 \pm 0.04$ & ns & 4 \\
\hline Vitamin C & {$[\mathrm{mg}]$} & 100 & $92.1 \pm 5.30$ & $152.0 \pm 0.95$ & $<.001$ & 66 & 100 & $86.2 \pm 8.50$ & $152.0 \pm 1.14$ & $<.001$ & 71 \\
\hline Sodium & {$[g]$} & 550 & $3321.7 \pm 119.01$ & $2494.0 \pm 9.41$ & $<.001$ & 0 & 550 & $3981.6 \pm 246.13$ & $3458.0 \pm 15.72$ & $<.05$ & 0 \\
\hline Potassium & {$[\mathrm{mg}]$} & 2000 & $2649.1 \pm 72.92$ & $3243.0 \pm 11.29$ & $<.001$ & 14 & 2000 & $2757.2 \pm 146.67$ & $3789.0 \pm 15.06$ & $<.001$ & 11 \\
\hline Calcium & {$[\mathrm{mg}]$} & 1000 & $979.9 \pm 46.72$ & $1019.0 \pm 4.33$ & ns & 63 & 1000 & $1020.4 \pm 75.47$ & $1143.0 \pm 5.93$ & ns & 61 \\
\hline Magnesium & {$[\mathrm{mg}]$} & 300 & $365.2 \pm 12.23$ & $376.0 \pm 1.23$ & ns & 29 & 350 & $380.9 \pm 23.01$ & $452.0 \pm 1.74$ & $<.05$ & 46 \\
\hline Iron & {$[\mathrm{mg}]$} & 15 & $12.9 \pm 0.36$ & $12.3 \pm 0.04$ & ns & 78 & 10 & $14.7 \pm 0.79$ & $15.2 \pm 0.06$ & ns & 7 \\
\hline Zinc & [mg] & 7 & $12.0 \pm 0.36$ & $9.5 \pm 0.03$ & $<.001$ & 3 & 10 & $14.2 \pm 0.71$ & $12.3 \pm 0.05$ & $<.05$ & 4 \\
\hline lodine & {$[\mu \mathrm{g}]$} & 200 & $83.9 \pm 4.08$ & $98.0 \pm 0.45$ & ns & 99 & 200 & $92.8 \pm 6.67$ & $107.0 \pm 0.5$ & ns & 100 \\
\hline
\end{tabular}

Abbreviations: DRI = Dietary Reference Intake, NNS II = National Nutrition Survey II.

Data are presented as mean $\pm \mathrm{SE}$.

${ }^{a}$ Recommendations for nutrient intake in Germany, Austria and Switzerland (D-A-CH reference values)[18].

${ }^{\mathrm{b}}$ Obese study population compared to German reference population (NNS II). 
Table 5 Serum micronutrient levels and deficiencies in obese subjects before and after low-calorie diet $(n=14)$

\begin{tabular}{|c|c|c|c|c|c|c|}
\hline & & \multicolumn{2}{|c|}{ Before formula diet } & \multicolumn{2}{|c|}{ After formula diet } & \multirow[b]{2}{*}{$p^{a}$} \\
\hline & & Mean \pm SD & Deficiency [\%] & Mean \pm SD & Deficiency [\%] & \\
\hline Vitamin A & {$[\mathrm{mg} / \mathrm{l}]$} & $0.67 \pm 0.19$ & 0 & $0.78 \pm 0.22$ & 0 & n.s. \\
\hline Vitamin E & {$[\mathrm{mg} / \mathrm{l}]$} & $11.57 \pm 4.31$ & 0 & $12.54 \pm 2.66$ & 0 & n.s. \\
\hline $25(\mathrm{OH}) \mathrm{D}$ & {$[\mathrm{ng} / \mathrm{ml}]$} & $17.22 \pm 4.02$ & 57.1 & $24.32 \pm 7.25$ & 30.8 & $<.01$ \\
\hline Vitamin C & {$[\mathrm{mg} / \mathrm{l}]$} & $52.01 \pm 10.65$ & 10.0 & $43.86 \pm 15.96$ & 25.0 & n.s. \\
\hline Vitamin $B_{12}$ & {$[\mathrm{pg} / \mathrm{ml}]$} & $474.1 \pm 155.3$ & 0 & $528.3 \pm 165.3$ & 0 & n.s. \\
\hline Folate & {$[\mathrm{ng} / \mathrm{ml}]$} & $10.51 \pm 4.7$ & 0 & $15.42 \pm 4.9$ & 0 & $<.05$ \\
\hline Selenium & {$[\mu \mathrm{g} / \mathrm{l}]$} & $87.71 \pm 11.74$ & 14.3 & $95.42 \pm 18.67$ & 16.7 & $<.05$ \\
\hline Iron & {$[\mu \mathrm{g} / \mathrm{dl}]$} & $81.50 \pm 35.05$ & 14.3 & $61.62 \pm 26.17)$ & 15.4 & $<.05$ \\
\hline Zinc & {$[\mu \mathrm{g} / \mathrm{dl}]$} & $82.14 \pm 10.64$ & 0 & $94.85 \pm 13.80$ & 7.7 & $<.01$ \\
\hline Calcium & {$[\mathrm{mmol} / \mathrm{l}]$} & $2.44 \pm 0.10$ & 0 & $2.18 \pm 0.28$ & 53.8 & $<.01$ \\
\hline
\end{tabular}

a $\mathrm{p}$-values were calculated in relation to absolute values using paired t-tests.

\section{Correlations with C-reactive protein (CRP), body weight and body fat}

CRP concentrations positively correlated with body weight $(\mathrm{r}=0.6558, \mathrm{p}<0.0001)$. There was a negative correlation between iron and CRP $(\mathrm{r}=-0.456, \mathrm{p}<0.05)$. Lipophilic vitamins were negatively associated with body fat in percent of total body weight $(25(\mathrm{OH}) \mathrm{D}$ : $\mathrm{r}=-0,6369, \mathrm{p}<0.0001$, vitamin $\mathrm{A}: \mathrm{r}=-0,4663, \mathrm{p}<0.05$, vitamin $\mathrm{E}$ (serum): $\mathrm{r}=-0,4378, \mathrm{p}<0.05)$.

\section{Discussion}

The present study clearly confirms previous observations stating that obese individuals are characterized by micronutrient deficiencies [4,6-8,10-13]. The deficiencies are suggested by both low intake and low serum and intracellular levels as shown by our data.

The study demonstrates an insufficient dietary micronutrient supply of retinol, ß-carotene, vitamin $\mathrm{D}$, vitamin $\mathrm{E}$, vitamin $\mathrm{C}$, folate, iron, and calcium in obese individuals. A highly significant difference compared to the reference population, both in men and women, was observed for $\beta$-carotene, folate, vitamin $\mathrm{C}$, and fiber nutrients which are essentially found in fruits, vegetables and whole-grain products, thus pointing to an unbalanced diet leading to micronutrient deficiencies.

Evaluation of nutritional intake has some methodological weakness such as underreporting that limits the interpretation of dietary record data. The resulting error is possibly even more distinct in obese subjects [21-24]. However, underreporting especially applies to carbohydrate-rich snacks [25], which are low in micronutrient content by nature, and not to 'healthy' food. Therefore we assume that this error is negligible regarding micronutrient intake.

Before intervention, obese subjects showed deficiencies of several micronutrients in serum or BMC, namely 25 $(\mathrm{OH})$ vitamin $\mathrm{D}$, vitamin $\mathrm{C}$, selenium, iron, $ß$-carotene and lycopene. We did not find any statistically significant correlation between micronutrient intake and serum or BMC concentrations, which could be due to the limited subject number. However, the reported intakes of $\mathrm{B}$ carotene, vitamin $\mathrm{D}$, vitamin $\mathrm{C}$, and iron were clearly below DRI and point to a relation between micronutrient intake and body micronutrient status.

Based on our data, we conclude that a DRI-covering low-calorie formula diet does not meet the demands of obese individuals. The reasons can be manifold and could cover metabolic alterations during a period of major weight loss, unbalanced dispersal of lipophilic compounds and fat-tissue specific oxidative stress. Indeed, we observed even more subjects with deficiencies in some micronutrients after a three-month period of formula diet compared to the baseline status before intervention. In particular, vitamin $C$, selenium, iron, zinc, and lycopene deficiencies increased or could not be corrected by protein-rich formula diet containing vitamins and minerals according to DRI. The formula meal replacement products contained micronutrients in amounts often even higher than those recommended for the general population. We also observed an increase in subjects with calcium deficiency. However, serum calcium concentration is not an adequate measure for dietary calcium intake, but indicates an electrolyte imbalance induced by weight loss and accompanying fluid changes in the body.

Possible interaction effects between pharmaceuticals and micronutrients have to be considered, which may account for increased demands. Within this study, frequency and dosage of drug use did not change during the LCD period in most of the cases and thus most likely did not confound the results. In $36 \%$ of the subjects the dosage of at least one drug was slightly reduced, which would, if anything, have improved micronutrient bioavailability. 
(a)

Iron

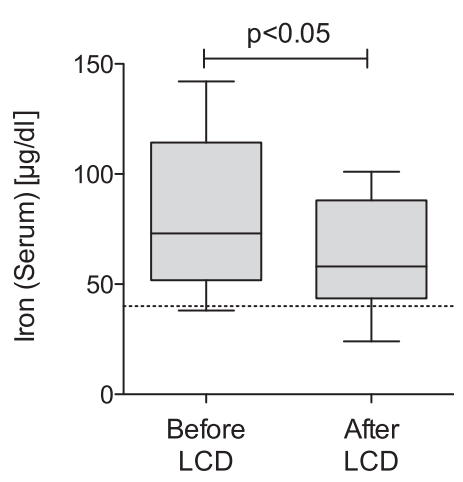

Calcium

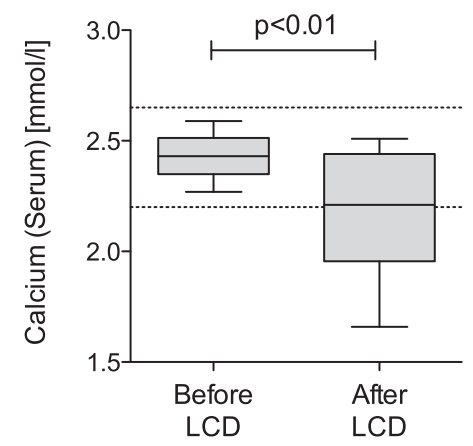

Vitamin C

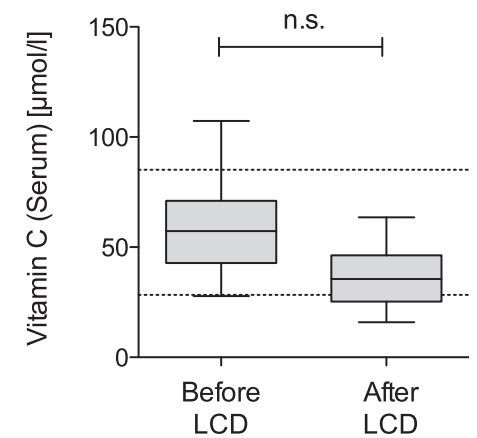

(b)

25(OH) Vitamin D

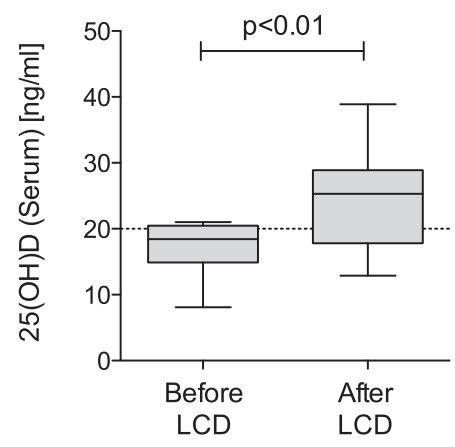

Folate

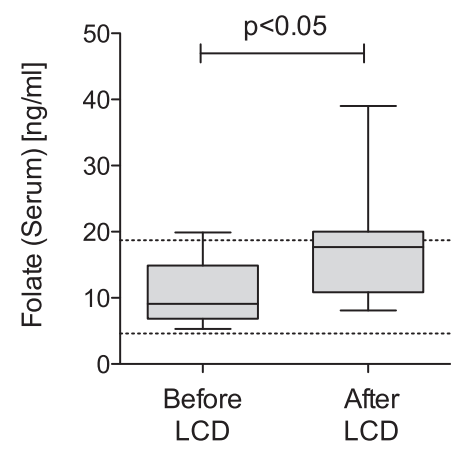

Zinc

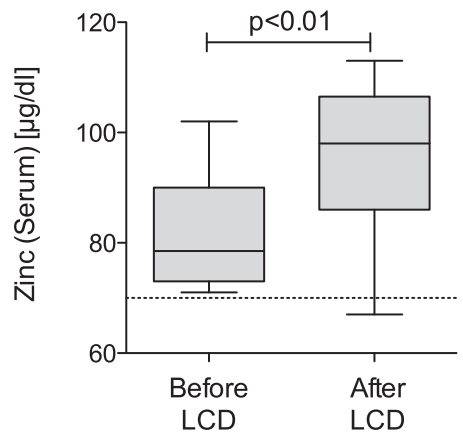

Figure 1 Serum micronutrients levels that decreased (a) or increased (b) in the course of intervention using a DRI- covering low-calorie formula diet $(\mathbf{n}=\mathbf{1 4})$. The dotted lines indicate the reference limits for adequate serum levels. Data are presented as median $+/-$ quartiles (boxes) and 1.5 interquartile ranges (whiskers).

We did not find statistically significant correlations between vitamin $\mathrm{E}$ in serum and $\mathrm{BMC}$, but the decrease in $\mathrm{BMC}$ concentrations could point to the fact that intracellular levels respond more sensitively to altered oxidative stress, which particularly occurs in a period of major weight loss [26]. This is explained by an upregulation of the renin-angiotensin system and a reduction of glutathione and glutathione peroxidase in erythrocytes, resulting in higher concentrations of reactive oxygen species which again promote the metabolic syndrome [6]. All three lipophilic vitamins negatively correlated with total body fat, assessed by bioelectric impedance analysis. This is most likely due to the storage capacity for lipophilic compounds, which is so far only suggested 


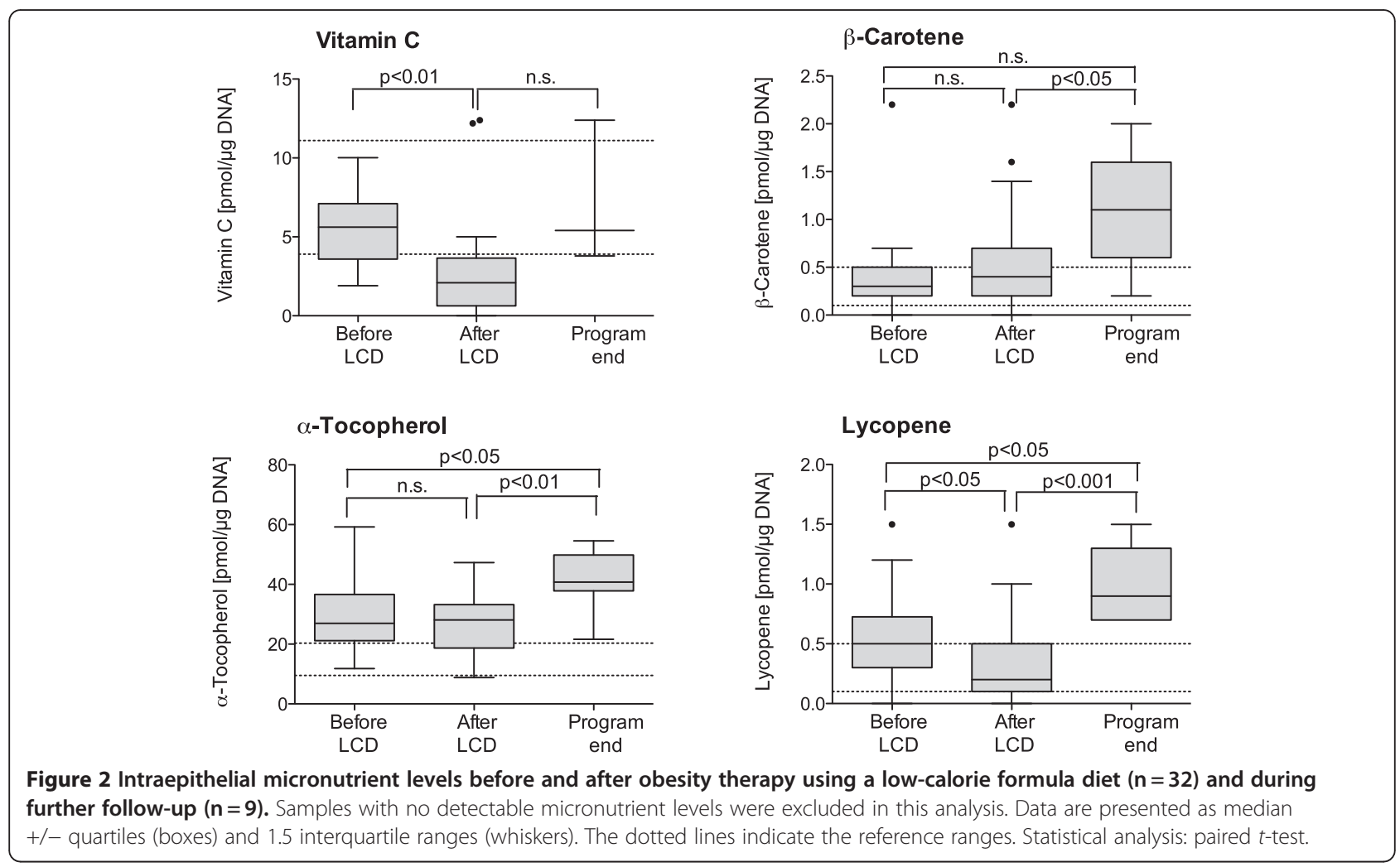

for $25(\mathrm{OH}) \mathrm{D}[27,28]$. It is tempting to speculate that this also applies to other lipophilic compounds. Thus, a higher amount of fat tissue could lead to an increase in accumulation of lipophilic vitamins, which in turn are lacking in the serum pool. The positive association between adipose tissue mass and systemic $25(\mathrm{OH}) \mathrm{D}$ concentrations, the almost 2 fold reduction of $25(\mathrm{OH}) \mathrm{D}$ deficiency following LCD, and the significant increase in $25(\mathrm{OH}) \mathrm{D}$ serum concentrations observed in our study all suggest storage in adipose tissue and release during weight loss, also described elsewhere $[29,30]$.
McClung et al. [31] hypothesized that obesity influences iron absorption by inflammatory mediated mechanisms. Proinflammatory cytokines promote hepcidin release in liver and fat tissue, which is involved in iron homeostasis, inhibiting absorption in enterocytes [31]. This hypothesis is supported by a significantly negative correlation of iron concentration with CRP levels observed in our obese subjects.

Measurement of vitamins in blood samples might not reflect the amount of vitamins absorbed or the concentration in tissues $[32,33]$. To gain information on body distribution (a)

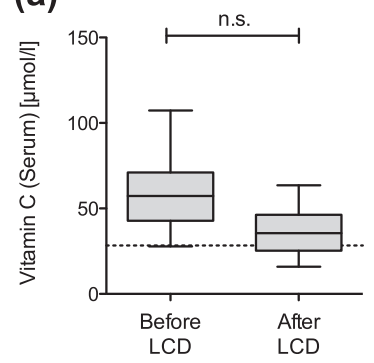

(b)

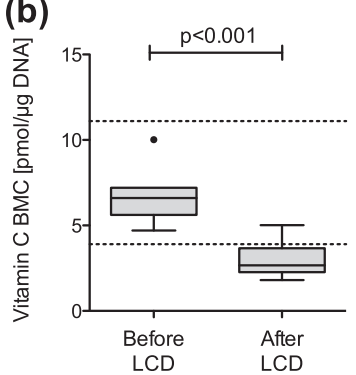

(c)

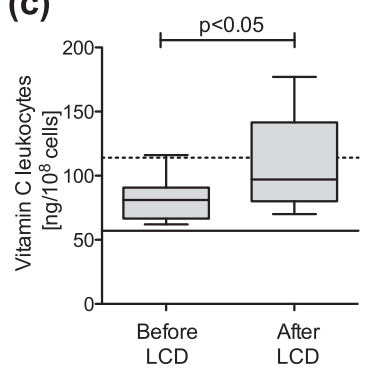

Figure 3 Comparison of vitamin C levels determined in serum (a) or intracellular, either in buccal epithelial cells (b) or in peripheral blood leukocytes (c), of obese patients who underwent a DRI-covering low-calorie formula diet program $(n=14)$. The dotted lines indicate the reference limits for adequate serum levels, the continuous line separates the 'low level range' from 'manifest deficiency range' according to reference data from healthy populations. Data are presented as median $+/$ - quartiles (boxes) and 1.5 interquartile ranges (whiskers). BMC samples below detection level were excluded from this analysis. 
we monitored both serum and intracellular levels of vitamins. BMC are easily available and serve as a model system for assessment of the nutritional and antioxidative status, as well as to control for the success of supplementation and effect of medicamentous therapies [33-35]. With a cellular turnover of 5 to 25 days, BMC are supposed to reflect the current cellular supply [36].

We evaluated the level of vitamin $C$, lycopene, $\alpha-$ tocopherol, and $B$-carotene and thus the antioxidative capacity directly in BMC. These dietary-derived antioxidants are an important component to support the exogenous antioxidative system [33]. Except for $\beta$-carotene and $\alpha$ tocopherol, which were only slightly reduced, we observed a significant decrease in vitamin $C$ and lycopene during the three-month formula diet suggesting again an enhanced oxidative stress in obese individuals and thus a higher demand of antioxidative vitamins compared to healthy, normal weight subjects, especially in a period of major weight loss.

The current choices for functional markers of vitamin C status are vitamin $\mathrm{C}$ concentrations in plasma and leukocytes. Plasma or serum vitamin $C$ levels are highly sensitive to recent dietary intakes, but may not reflect tissue content as well as leukocyte levels $[37,38]$. Serum vitamin C concentrations remained unchanged during the vitamin $C$ enriched formula diet, whereas leukocyte levels improved. Leukocyte concentrations more reliably display long-term supply and deficiencies $[37,38]$. Bioavailability of vitamin C is a complex issue involving distribution to the tissues and utilization by the tissues [35]. Before intervention, leukocyte levels were depleted and might replete preferentially due to their high metabolic priority [37]. Contrary to our expectations intracellular vitamin $\mathrm{C}$ concentrations in $\mathrm{BMC}$ significantly decreased. To obtain a state of complete saturation, the repletion dynamics of vitamin $C$ in certain tissues may be more specific than others when the vitamin intake during repletion is limited [37]. However, the results should be interpreted carefully because of the small sample size, the variation of vitamin $\mathrm{C}$ content throughout cell types and the reliability of sampling and analysis procedure due to the unstable nature of vitamin $C$. In contrast to the fat-soluble antioxidants $\alpha$-tocopherol, lycopene and $\beta$ carotene, which were demonstrated to be reliable markers in BMC $[32,33,35,39,40]$, the capacity of BMC vitamin C concentrations and its reliability as a biomarker for vita$\min C$ status has not been described so far.

Interestingly, we observed a significant increase in all antioxidants measured in BMC at the end of the program year. This subgroup only included nine subjects, but suggests a change in dietary habits following intensive weight reduction and diet counseling. These subjects were successful in losing weight and were able to maintain this weight after the formula diet, therefore most likely putting their nutritional knowledge into practice. However, this finding needs to be confirmed by other studies.

A potential limitation of the study is that the dietary assessment strategies differed in the two study populations. In the NNSII a comprehensive dietary history method including cross-check features was used. The dietary record approach in this study was chosen to provide quantitatively accurate information on food consumption as well as influence of food processing, but may be biased due to the estimation of the weight of food consumed in some cases instead of weighing, and also by affecting eating behavior. Moreover, for several micronutrients simple blood concentrations were measured, which might not always reflect a complete picture of the nutritional status. At this stage we only included a small sample size, which limits the explanatory power of the study results.

\section{Conclusions}

To the best of our knowledge, this is the first report analyzing if DRI of micronutrients meet the demands of obese individuals consuming a standardized LCD diet. Our pilot study provides evidence that a poor micronutrient status in obesity is not only caused by intakes that are below the DRI. A formula diet providing 100\% of micronutrients according to DRI did not cover the demands of some micronutrients in obese subjects. This can be explained by metabolic alterations during a period of major weight loss, unbalanced dispersal of lipophilic compounds and fat-tissue specific oxidative stress. The underlying mechanisms should be further addressed, as well as whether obese individuals receiving an energy-balanced DRI-covering diet also manifest micronutrient deficiencies.

\section{Competing interest}

All authors declare no competing interest; they are all independent from funders. SCB and ADM are part of the Competence network of obesity, which is largely funded by a research grant of the Federal Ministry of Education and Research, Germany; within this network, the research group of SCB is funded in part by Nestlé HealthCare Nutrition GmbH, Munich, Germany. The sponsors had no influence in study design, analysis, and interpretation of data, as well as in the writing of the manuscript. No other relationships or activities exist that could appear to have influenced the submitted work

\section{Acknowledgement}

This work was supported by the "Competence Network of Obesity", research group "Obesity and the Gl tract,"funded by the Federal Ministry of Education and Research, Germany (No. FKZ 01 Gl0843 to SCB), and by Nestlé HealthCare Nutrition $\mathrm{GmbH}$, Munich, Germany, who is part of the "Competence Network of Obesity"

\section{Author details}

${ }^{1}$ Department of Nutritional Medicine, University of Hohenheim, Stuttgart, Germany. 'Department of Nutritional Medicine, University of Hohenheim, Fruwirthstr. 12, ss70599, Stuttgart, Germany.

\section{Authors' contributions}

The study was designed by ADM and SCB. ADM and GW carried out the study, collected, and analyzed the data. ADM drafted the manuscript. SCB 
reviewed the manuscript. All authors read and approved the final manuscript.

Received: 2 January 2012 Accepted: 1 June 2012 Published: 1 June 2012

\section{References}

1. Schneider A: Malnutrition with Obesity. Aktuelle Ernährungsmedizin 2008, 33:280-283.

2. Grzybek A, Klosiewicz-Latoszek L, Targosz U: Changes in the intake of vitamins and minerals by men and women with hyperlipidemia and overweight during dietetic treatment. Eur J Clin Nutr 2002, 56:1162-1168.

3. Aasheim ET, Hofso D, Hjelmesaeth J, Birkeland Kl, Bohmer T: Vitamin status in morbidly obese patients: a cross-sectional study. Am J Clin Nutr 2008, 87:362-369.

4. Ernst B, Thurnheer M, Schmid SM, Schultes B: Evidence for the necessity to systematically assess micronutrient status prior to bariatric surgery. Obes Surg 2009, 19:66-73.

5. Xanthakos SA: Nutritional deficiencies in obesity and after bariatric surgery. Pediatr Clin North Am 2009, 56:1105-1121.

6. Kimmons JE, Blanck HM, Tohill BC, Zhang J, Khan LK: Associations between body mass index and the prevalence of low micronutrient levels among US adults. MedGenMed 2006, 8:59.

7. Kaidar-Person O, Person B, Szomstein S, Rosenthal RJ: Nutritional deficiencies in morbidly obese patients: a new form of malnutrition? Part B: minerals. Obes Surg 2008, 18:1028-1034.

8. Madan AK, Orth WS, Tichansky DS, Ternovits CA: Vitamin and trace mineral levels after laparoscopic gastric bypass. Obes Surg 2006, 16:603-606.

9. Sanchez C, Lopez-Jurado M, Aranda P, Llopis J: Plasma levels of copper, manganese and selenium in an adult population in southern Spain: influence of age, obesity and lifestyle factors. Sci Total Environ 2010, 408:1014-1020.

10. Brolin RE, Gorman JH, Gorman RC, Petschenik AJ, Bradley LJ, Kenler HA, Cody RP: Are vitamin B12 and folate deficiency clinically important after roux-en-Y gastric bypass? J Gastrointest Surg 1998, 2:436-442.

11. Flancbaum L, Belsley S, Drake V, Colarusso T, Tayler E: Preoperative nutritional status of patients undergoing Roux-en- $Y$ gastric bypass for morbid obesity. J Gastrointest Surg 2006, 10:1033-1037.

12. Skroubis G, Sakellaropoulos G, Pouggouras K, Mead N, Nikiforidis G, Kalfarentzos F: Comparison of nutritional deficiencies after Roux-en-Y gastric bypass and after biliopancreatic diversion with Roux-en-Y gastric bypass. Obes Surg 2002, 12:551-558.

13. Kaidar-Person O, Person B, Szomstein S, Rosenthal RJ: Nutritional deficiencies in morbidly obese patients: a new form of malnutrition? Part A: vitamins. Obes Surg 2008, 18:870-876.

14. Bourre JM: Effects of nutrients (in food) on the structure and function of the nervous system: update on dietary requirements for brain. Part 1 : micronutrients. J Nutr Health Aging 2006, 10:377-385.

15. Reynolds E: Vitamin B12, folic acid, and the nervous system. Lancet Neurol 2006, 5:949-960

16. Muscogiuri G, Sorice GP, Prioletta A, Policola C, Della Casa S, Pontecorvi A, Giaccari A: 25-Hydroxyvitamin D concentration correlates with insulinsensitivity and BMI in obesity. Obesity (Silver Spring) 2010, 18:1906-1910.

17. Institute of Medicine, Food and Nutrition Board: Dietary Reference Intakes RDA and Al for Vitamins and Elements.[http://fnic.nal.usda.gov/]

18. Wolfram G: New reference values for nutrient intake in Germany, Austria and Switzerland (DACH-Reference Values). Forum Nutr 2003, 56:95-97.

19. Bischoff SC, Damms-Machado A, Betz C, Herpertz S, Legenbauer T, Low T, Wechsler JG, Bischoff G, Austel A, Ellrott T: Multicenter evaluation of an interdisciplinary 52-week weight loss program for obesity with regard to body weight, comorbidities and quality of life-a prospective study. Int J Obes (Lond) 2012, 36:614-624.

20. Denson KW, Bowers EF: The determination of ascorbic acid in white blood cells. A comparison of W.B.C. ascorbic acid and phenolic acid excretion in elderly patients. Clin Sci 1961, 21:157-162.

21. Bandini LG, Schoeller DA, Cyr HN, Dietz WH: Validity of reported energy intake in obese and nonobese adolescents. Am J Clin Nutr 1990, 52:421-425.

22. Goris AH, Westerterp-Plantenga MS, Westerterp KR: Undereating and underrecording of habitual food intake in obese men: selective underreporting of fat intake. Am J Clin Nutr 2000, 71:130-134.
23. Lichtman SW, Pisarska K, Berman ER, Pestone M, Dowling H, Offenbacher E, Weisel H, Heshka S, Matthews DE, Heymsfield SB: Discrepancy between self-reported and actual caloric intake and exercise in obese subjects. $N$ Engl J Med 1992, 327:1893-1898.

24. Pryer JA, Vrijheid M, Nichols R, Kiggins M, Elliott P: Who are the 'low energy reporters' in the dietary and nutritional survey of British adults? Int J Epidemiol 1997, 26:146-154.

25. Poppitt SD, Swann D, Black AE, Prentice AM: Assessment of selective under-reporting of food intake by both obese and non-obese women in a metabolic facility. Int J Obes Relat Metab Disord 1998, 22:303-311.

26. Yanagawa Y, Morimura T, Tsunekawa K, Seki K, Ogiwara T, Kotajima N, Machida T, Matsumoto S, Adachi T, Murakami M: Oxidative stress associated with rapid weight reduction decreases circulating adiponectin concentrations. Endocr J 2010, 57:339-345.

27. Wortsman J, Matsuoka LY, Chen TC, Lu Z, Holick MF: Decreased bioavailability of vitamin D in obesity. Am J Clin Nutr 2000, 72:690-693.

28. Earthman CP, Beckman LM, Masodkar K, Sibley SD: The link between obesity and low circulating 25-hydroxyvitamin D concentrations: considerations and implications. Int J Obes (Lond) 2012, 36:387-396.

29. Lin E, Armstrong-Moore D, Liang Z, Sweeney JF, Torres WE, Ziegler TR, Tangpricha V, Gletsu-Miller N: Contribution of adipose tissue to plasma 25-hydroxyvitamin D concentrations during weight loss following gastric bypass surgery. Obesity (Silver Spring) 2011, 19:588-594.

30. Damms-Machado A, Friedrich A, Kramer K, Stingel K, Meile T, Küper M, Königsrainer A, Bischoff SC: Pre- and postoperative nutritional deficiencies in obese patients undergoing laparoscopic sleeve gastrectomy. Obes Surg 2012, 22:881-889.

31. McClung JP, Karl JP: Iron deficiency and obesity: the contribution of inflammation and diminished iron absorption. Nutr Rev 2009, 67:100-104.

32. Peng YM, Peng YS, Lin Y, Moon T, Roe DJ, Ritenbaugh C: Concentrations and plasma-tissue-diet relationships of carotenoids, retinoids, and tocopherols in humans. Nutr Cancer 1995, 23:233-246.

33. Erhardt JG, Mack H, Sobeck U, Biesalski HK: beta-Carotene and alpha-tocopherol concentration and antioxidant status in buccal mucosal cells and plasma after oral supplementation. Br J Nutr 2002, 87:471-475.

34. Sobeck U, Fischer A, Biesalski HK: Uptake of vitamin A in buccal mucosal cells after topical application of retinyl palmitate: a randomised, placebo-controlled and double-blind trial. Br J Nutr 2003, 90:69-74.

35. Paetau I, Rao D, Wiley ER, Brown ED, Clevidence BA: Carotenoids in human buccal mucosa cells after 4 wk of supplementation with tomato juice or lycopene supplements. Am J Clin Nutr 1999, 70:490-494.

36. Gillespie GM: Renewal of buccal epithelium. Oral Surg Oral Med Oral Pathol 1969, 27:83-89.

37. Jacob RA: Assessment of human vitamin C status. J Nutr 1990, 120 (Suppl 11):1480-1485.

38. Yamada H, Yamada K, Waki M, Umegaki K: Lymphocyte and plasma vitamin $C$ levels in type 2 diabetic patients with and without diabetes complications. Diabetes Care 2004, 27:2491-2492.

39. Gabriel HE, Liu Z, Crott JW, Choi SW, Song BC, Mason JB, Johnson EJ: A comparison of carotenoids, retinoids, and tocopherols in the serum and buccal mucosa of chronic cigarette smokers versus nonsmokers. Cancer Epidemiol Biomarkers Prev 2006, 15:993-999.

40. Reifen R, Haftel L, Faulks R, Southon S, Kaplan I, Schwarz B: Plasma and buccal mucosal cell response to short-term supplementation with all trans-beta-carotene and lycopene in human volunteers. Int J Mol Med 2003, 12:989-993.

\section{doi:10.1186/1475-2891-11-34}

Cite this article as: Damms-Machado et al:: Micronutrient deficiency in obese subjects undergoing low calorie diet. Nutrition Journal 2012 11:34. 